\section{Kidney \\ Blood Pressure Research}

\title{
Influence of the Method of Definition on the Prevalence of Left-Ventricular Hypertrophy in Children with Chronic Kidney Disease: Data from the Know-Ped CKD Study
}

\author{
Heeyeon Cho ${ }^{a}$ Hyun Jin Choi ${ }^{b}$ Hee Gyung Kang ${ }^{b}$ Il-Soo Ha ${ }^{b}$ \\ Hae Il Cheong ${ }^{b}$ Kyung Hee Hanc Seong Heon Kim ${ }^{d}$ Min Hyun Cho \\ Jae Il Shin ${ }^{f}$ Joo Hoon Leeg Young Seo Park ${ }^{g}$
}

\begin{abstract}
aDepartment of Pediatrics, Samsung Medical Center, Sungkyunkwan University School of Medicine, Seoul; ${ }^{b}$ Department of Pediatrics, Seoul National University Children's Hospital, Seoul; 'Department of Pediatrics, Jeju University Hospital, Jeju; ${ }^{d}$ Department of Pediatrics, Pusan National University Children's Hospital, Yangsan; eDepartment of Pediatrics, Kyungpook National University School of Medicine, Daegu; 'Department of Pediatrics, Yonsei University College of Medicine, Severance Children's Hospital, Seoul; ${ }^{9}$ Department of Pediatrics, Asan Medical Center, University of Ulsan College of Medicine, Seoul, South Korea
\end{abstract}

\section{Key Words}

Chronic kidney disease $\bullet$ Left-ventricular hypertrophy $\bullet$ Children

\begin{abstract}
Background/Aims: Children with chronic kidney disease (CKD) have a high risk of cardiovascular disease. Left-ventricular (LV) hypertrophy (LVH) is an early marker of cardiovascular disease in pediatric CKD, and the prevalence of LVH in pediatric CKD is approximately $20-30 \%$ in predialysis CKD patients. However, there is no consensus on the ideal method of defining LVH in pediatric CKD patients. Previous studies have typically used the LV mass index (LVMI), which is calculated as LV mass in grams divided by height in meters to the $2.7^{\text {th }}$ power $\geq 38 \mathrm{~g} / \mathrm{m}^{2.7}$, to diagnose LVH in children with CKD. Recently, age-specific reference values for LVMI $\geq 95^{\text {th }}$ percentile and LV wall-thickness $z$-score $>1.64$ in children were addressed. The aim of this study was to assess the prevalence and contributing factors of LVH in pediatric CKD patients according to each measurement and evaluate the concordance between each measurement. Methods: We used the baseline data of the KoreaN cohort study for Outcome in patients With Pediatric Chronic Kidney Disease (KNOW-Ped CKD), which is a nationwide, 10-year, prospective,
\end{abstract}




\section{Kidney Blood Pressure Research}

observational cohort study of pediatric CKD. A total of 469 patients were enrolled, and 458 patients were included in the final analysis. Univariate and multiple logistic regression analysis were performed to evaluate the association of the variables with LVH. Kappa statistics were used to analyze the concordance. Results: According to an LVH diagnosis of LVMI $\geq 38 \mathrm{~g} / \mathrm{m}^{2.7}$, 188 patients (41.0\%) were diagnosed with LVH, and the prevalence of LVH was high in younger patients ( $<2$ years of age). Using the age-specific reference values, 116 patients $(25.3 \%)$ were diagnosed with $\mathrm{LVH}$, and there was no difference in the prevalence of LVH according to age. Thirty-one patients (6.8\%) were diagnosed with LVH using an LV wall-thickness $z$-score > 1.64. There is poor concordance between the diagnosis of LVH using the LV wall-thickness $z$-score and the LVMI method. Conclusions: The results of this study show that there is poor concordance between the diagnosis of LVH using the wall-thickness $z$-score and the $\mathrm{LVMI}^{2.7}$ criteria. Further investigation is needed to estimate the correlation between LVH and cardiac dysfunction and to find a better method for defining LVH in the pediatric CKD cohort and thereby predicting cardiac dysfunction.

(C) 2017 The Author(s)

Published by S. Karger AG, Basel

\section{Introduction}

Children with chronic kidney disease (CKD) are at a high risk of cardiovascular disease, and it was previously reported that cardiovascular disease accounts for $23 \%$ of deaths in pediatric and young adult end-stage renal disease patients [1]. The lifespan of children on dialysis was estimated to be shortened by 50 years compared with the control group [2]. The risk factors for cardiovascular disease in CKD include fluid retention, anemia, hypertension, dysregulated metabolism of calcium and phosphorus, and chronic inflammation [2].

Left-ventricular (LV) hypertrophy (LVH) is the most common cardiac alteration and an early marker of cardiovascular disease in pediatric CKD [3]. It has been reported that LVH and diastolic dysfunction are present in early-stage pediatric CKD $[4,5]$. The prevalence of LVH is approximately $20-30 \%$ in pre-dialysis pediatric CKD patients [2, 3]. In dialysis patients, LVH is usually correlated with hypertension and volume overload, and one report stated that the prevalence is as high as $85 \%$ in children on dialysis [3]. Recent reports suggest that effective renal replacement therapy, such as kidney transplantation and peritoneal dialysis, could improve LVH in patients with end-stage renal disease [6, 7].

In general, a diagnosis of LVH is made using echocardiography on the basis of the LV mass index (LVMI) to normalize LV mass to body size, and there are a variety of methods to define LVMI that have been used in children and adults. In adults, LVMI is usually calculated by dividing LV mass (in grams) by body surface area [8]. LV mass increases in a cubic exponential relationship with body height in healthy children, and the recommended calculation for LVMI in children is usually acquired by dividing LV mass by height in meters raised to the allometric power of 2.7 [9]. However, there is no consensus on the ideal method of defining LVH in pediatric CKD patients. Previous studies in CKD have typically used LVMI $\geq 38.6 \mathrm{~g} / \mathrm{m}^{2.7}$ to diagnose LVH because the cut-off of $38.6 \mathrm{~g} / \mathrm{m}^{2.7}$ represents the $95^{\text {th }}$ percentile of the healthy pediatric population $[10,11]$. One report recommended that an LVMI of $51 \mathrm{~g} / \mathrm{m}^{2.7}$ should be used for the diagnosis of LVH because this cut-off is associated with cardiovascular morbidity in patients with hypertension [12]. Recently, age-specific reference values for LVMI $\geq 95^{\text {th }}$ percentile were addressed, and it was recommended that LV mass/height ${ }^{2.7}$ should be compared with percentile curves for patients aged $<9$ years [13]. However, there is a question as to whether LVMI $\left(\mathrm{g} / \mathrm{m}^{2.7}\right)$ accurately represents the relationship between LV mass and body size throughout a child's growth. A novel method of expressing LV mass relative to body size in children was reported in which LV mass-for-height centile curves were proposed to be superior to LVMI $\left(\mathrm{g} / \mathrm{m}^{2.7}\right)$ as a method of normalizing $\mathrm{LV}$ mass to body size in children [14]. According to this novel method, those with an LV mass above the $95^{\text {th }}$ percentile for height (i.e., $\mathrm{LV}$ wall-thickness $z$-score $>1.64$ ) were classified as 


\section{Kidney Blood Pressure Research}

Cho et al.: Definition of Left-Ventricular Hypertrophy

having LVH [14]. Recently, a report analyzed the concordance of the LVMI $\left(\mathrm{g} / \mathrm{m}^{2.7}\right)$ and the LV mass $z$-score in the diagnosis of LVH in children with hypertension [15]. However, there was little data analyzing the concordance of the methods to define LVH in children with CKD.

The aim of this study was to assess the prevalence and contributing factors of LVH in pediatric CKD patients according to each measurement and evaluate the concordance between each measurement in the diagnosis of LVH in a pediatric CKD cohort.

\section{Materials and Methods}

Study design and population

We used the baseline data of the KoreaN cohort study for Outcome in patients With Pediatric Chronic Kidney Disease (KNOW-Ped CKD), a nationwide, 10-year, prospective, observational cohort study of pediatric CKD, including CKD stage 1-5 pediatric patients, from April 2011 to February 2016. Seven major pediatric nephrology centers in Korea have participated in the study and enrolled 469 children with CKD for the comprehensive assessment of the clinical findings. The detailed design and methods of the KNOW-Ped CKD were published [16]. Detailed information was also previously described elsewhere (NCT02165878 at http://www.clinicaltrials.gov). This study protocol was approved by the institutional review board at each participating clinical center in 2011. All of the participants provided written informed consent encompassing the study's purpose, duration, procedures, alternatives, risks, benefits, and subject's rights to withdraw from the study at any time. Among the 469 patients initially included, 11 children were excluded because of the violation of the inclusion criteria, withdrawal of consent or a transfer to another center not participating in the study; a total of 458 patients were included in the final analysis.

\section{Ethical statement}

All of the data were obtained in accordance with the ethical principles for medical research involving human subjects established in the Helsinki Declaration of 1975 and revised in 2000.

\section{Clinical and laboratory measurements}

Data on medical history, medication use, socio-economic status, and quality of life were collected through a self-administered questionnaire. The definition of co-morbidity included heart failure, arrhythmia, urinary tract infection, diabetes, retinopathy, sensorineural hearing loss, developmental delay, and metabolic syndrome. The biochemical values were measured at the hospital laboratory of each participating center, and serum samples were sent to the central laboratory (Lab Genomics, Korea) for measurement of creatinine, intact parathyroid hormone (iPTH), and 25-OH vitamin D. CKD was defined and staged according to the Kidney Disease Improving Global Outcomes (KDIGO) criteria [17]. The estimated glomerular filtration rate (eGFR) was calculated using the bedside CKiD formula [18].

Blood pressure (BP) was measured using a mercury sphygmomanometer after the subject had rested for $5 \mathrm{~min}$ in a sitting position. All BP measurements were taken on the right arm three times with a cuff appropriate for arm circumference. The average value of the second and third measurements of systolic BP and diastolic BP were used for subsequent analyses and based on a decision for hypertension. The definition of hypertension was when the average value of the systolic and/or diastolic BP measurements were $\geq 95$ th percentile for age, gender, and height [19].

A chest X-ray and twelve-lead electrocardiogram were performed. Cardiomegaly is present when the cardiothoracic ratio is more than $55 \%$ on the chest X-ray, and the patient with cardiomegaly was regarded as LVH according to the chest X-ray. The electrocardiogram was interpreted at each center on the basis of published normal electrocardiogram standards for infants and children by Davignon et al [20].

Two-dimensional echocardiography was performed by pediatric cardiologists in each center to measure cardiac parameters according to the American Society of Echocardiography (ASE) pediatric guidelines [21]. LV mass was calculated from the M-mode measurements of the interventricular septum (IVS), LV inner dimension (LVID), and LV posterior wall thickness (LVPW) using the Devereux formula: $0.8 \times\left\{1.04\left[\left(\right.\right.\right.$ IVS + LVID + LVPW $^{3}$-(LVID) $\left.\left.{ }^{3}\right]\right\}+0.6 \mathrm{~g}[22,23]$. The relative wall thickness (RWT) was calculated to assess the LV geometry using the following formula: (IVS + LVPW)/(LVID). The cut-off value for RWT 


\section{Kidney Blood Pressure Research}

Kidney Blood Press Res 2017;42:406-415

\begin{tabular}{l|l}
\hline DOI: 10.1159/000478867 & (C) 2017 The Author(s). Published by S. Karger AG, Base
\end{tabular}

Published online: July 07, 2017 www.karger.com $/ \mathrm{kb}$

Cho et al.: Definition of Left-Ventricular Hypertrophy was 0.42 [24]. Based on LVMI and RWT, the LV geometry was categorized as either concentric hypertrophy (LVMI $\geq 38 \mathrm{~m}^{2.7}$ and RWT > 0.42), eccentric hypertrophy $\left(\mathrm{LVMI} \geq 38 \mathrm{~m}^{2.7}\right.$ and RWT $\left.\leq 0.42\right)$, concentric remodeling ( $\mathrm{LVMI}<38 \mathrm{~m}^{2.7}$ and RWT $>0.42$ ), or normal (LVMI $<38 \mathrm{~m}^{2.7}$ and RWT $\leq 0.42$ ).

Baseline demographics and clinical and laboratory values were extracted from the web-based data management system, PhactaX (version 1.0), with the assistance of the Division of Data Management of the Seoul National University Medical Research Collaborating Center.

\section{Statistical analysis}

Continuous variables are expressed as the mean \pm standard deviation or median (interquartile range). Continuous variables are compared between groups using the independent $t$-test, Kruskal-Wallis test and the Wilcoxon rank-sum test. Categorical variables are expressed as percentages and compared between groups with the Chi-square test and Fisher's exact test. The logistic regression analysis was used to determine the odds ratio (OR) and confidence interval (CI) for the presence of
Table 1. Demographic and clinical data in the entire patient cohort

\begin{tabular}{ll}
\hline Variables & $\begin{array}{l}\text { Total patient } \\
\text { cohort } \\
(\mathrm{n}=458)\end{array}$ \\
\hline Age (years) & $9.9 \pm 5.5$ \\
Sex (male/female) & $310 / 148$ \\
\hline Causes of chronic kidney disease & $66(14.4)$ \\
\hline \multicolumn{1}{c}{ Primary glomerulopathy } & $64(14.0)$ \\
Secondary glomerulopathy & $70(15.3)$ \\
Reflux nephropathy & $187(40.8)$ \\
Renal dysplasia/hypoplasia & $71(15.5)$ \\
Others & \\
\hline Chronic kidney disease stage & $71(15.5)$ \\
\hline I & $123(26.9)$ \\
II & $146(31.9)$ \\
III & $89(19.4)$ \\
IV & $29(6.3)$ \\
V & $5.8 \pm 4.8$ \\
Duration of primary disease (years) & $-0.4 \pm 1.4$ \\
Body mass index $z$-score & $12.2 \pm 2.0$ \\
Hemoglobin (g/dL) & $9.3 \pm 0.7$ \\
Serum Ca (mg/dL) & $4.8 \pm 1.0$ \\
Serum P (mg/dL) & $101.2 \pm 157.5$ \\
Intact parathyroid hormone (pg/mL) & $21.5 \pm 10.8$ \\
25 (OH) vitamin D (ng/mL) & $39.2 \pm 17.7$ \\
Left ventricular mass index (g/m2.7) & $66.9 \pm 7.3$ \\
Ejection fraction (\%) & $36.8 \pm 5.0$ \\
Fractional shortening (\%) & $148(32.5)$ \\
Patients receiving antihypertensive medications & \\
\hline Data are presented as the mean \pm standard deviation given in the \\
parentheses or as the number of patients with & the percentage \\
given in the parentheses & \\
\hline
\end{tabular}

LVH associated with each variable. Kappa statistics were used to analyze the concordance. Concordance was graded using 0 to indicate no concordance and 1 to represent complete concordance. Statistical analyses were performed using SPSS software, version 19.0 (SPSS Inc.).

\section{Results}

\section{Baseline characteristics of subjects}

Demographic and clinical data for the 458 patients are listed in Table 1 . The most common cause of CKD was congenital anomalies of the kidney and urinary tract (40.8\%), and 66 children (14.5\%) had primary glomerulonephritis.

Based on the heart to lung ratio from the chest X-ray, 86 patients $(18.8 \%)$ were diagnosed with LVH, which was associated with a younger age $(<2$ years of age, $P<0.0001)$, low body weight $(P=0.0002)$, low gestational age $(P<0.0001)$, and low birth weight $(P=0.0014)$ by univariate logistic regression. Although 17 patients $(53.1 \%)$ were diagnosed with LVH in the patients below 2 years, 36 patients $(11.1 \%)$ were compatible with LVH according to chest the $\mathrm{X}$-ray in those above 2 years. An electrocardiogram revealed that 38 patients (8.3\%) had LVH, which was associated with systolic hypertension $(P=0.0334)$ and short stature $(P=0.0374)$ by univariate logistic regression. However, there was no concordance between the diagnosis of LVH by chest X-ray and electrocardiogram. The Kappa coefficient showed a relatively low concordance value of 0.2351 between the chest X-ray and the electrocardiogram.

A total of 148 patients (32.5\%) received antihypertensive medications, and there was a significant difference in the proportion of patients with the antihypertensive medications according to age (Table 2). The levels of LVMI were higher in younger patients (especially, $<2$ years of age) compared to older children (Table 2). Eccentric hypertrophy was found in 


\section{Kidney Blood Pressure Research}

Table 2. Hypertension and left ventricular mass according to age

\begin{tabular}{|c|c|c|c|c|c|c|}
\hline & $\begin{array}{l}\text { Total } \\
(\mathrm{n}=458)\end{array}$ & $\begin{array}{l}0-2 \text { years } \\
(\mathrm{n}=43)\end{array}$ & $\begin{array}{l}2-6 \text { years } \\
(\mathrm{n}=77)\end{array}$ & $\begin{array}{l}6-12 \text { years } \\
(n=125)\end{array}$ & $\begin{array}{l}12-20 \text { years } \\
(\mathrm{n}=213)\end{array}$ & $P$-value \\
\hline $\begin{array}{l}\text { Number of patients receiving } \\
\text { antihypertensive medications (\%) }\end{array}$ & $148(32.5)$ & $8(18.6)$ & $13(16.9)$ & $40(32.0)$ & 87 (41.2) & $<0.001^{\mathrm{a}}$ \\
\hline $\operatorname{LVMI}\left(\mathrm{g} / \mathrm{m}^{2.7}\right)$ & $39.2 \pm 9.3$ & $60.3 \pm 0.32$ & $46.3 \pm 9.3$ & $37.7 \pm 8.4$ & $33.5 \pm 7.4$ & $<0.001^{\mathrm{b}}$ \\
\hline
\end{tabular}

LVMI, Left ventricular mass index, Data are presented as the mean \pm standard deviation in the parentheses or as the number of patients with the percentage given in parentheses, aThere was statistical significance by the Chi square test, bThere was statistical significance by the Kruskal-Wallis test

Table 3. Associated factors of left ventricular hypertrophy with the definition of LVMI $\geq 38 \mathrm{~g} / \mathrm{m}^{2.7}$

\begin{tabular}{lllll}
\hline & \multicolumn{2}{l}{ Univariate logistic regression } & \multicolumn{2}{l}{ Multivariable logistic regression } \\
\cline { 2 - 5 } & Unadjusted OR(95\% CI) & $P$-value & Adjusted OR(95\% CI) & $P$-value \\
\hline Age & $0.863(0.830,0.897)$ & $<0.0001$ & $0.880(0.829,0.935)$ & $<0.0001$ \\
BMI z-score & $1.393(1.177,1.648)$ & 0.0001 & $1.893(1.432,2.502)$ & $<0.0001$ \\
iPTH & $1.002(1.001,1.004)$ & 0.0028 & $1.004(1.002,1.006)$ & 0.0005 \\
Duration of primary disease & $0.871(0.831,0.913)$ & $<0.0001$ & $0.918(0.862,0.977)$ & 0.0072 \\
\hline
\end{tabular}

LVMI, Left ventricular mass index; OR, Odds ratio; CI, Confidence interval; BMI, Body mass index; iPTH, intact parathyroid hormone

Fig. 1. Concordance of the measures of left-ventricular hypertrophy in children with chronic kidney disease. In the patients with LVH diagnosed by LVMI $\geq 38 \mathrm{~g} /$ $\mathrm{m}^{2.7}, 114$ patients $(60.6 \%) \quad$ fulfill the criteria of LVH by age-specific reference $\geq 95$ percentile. Among the 114

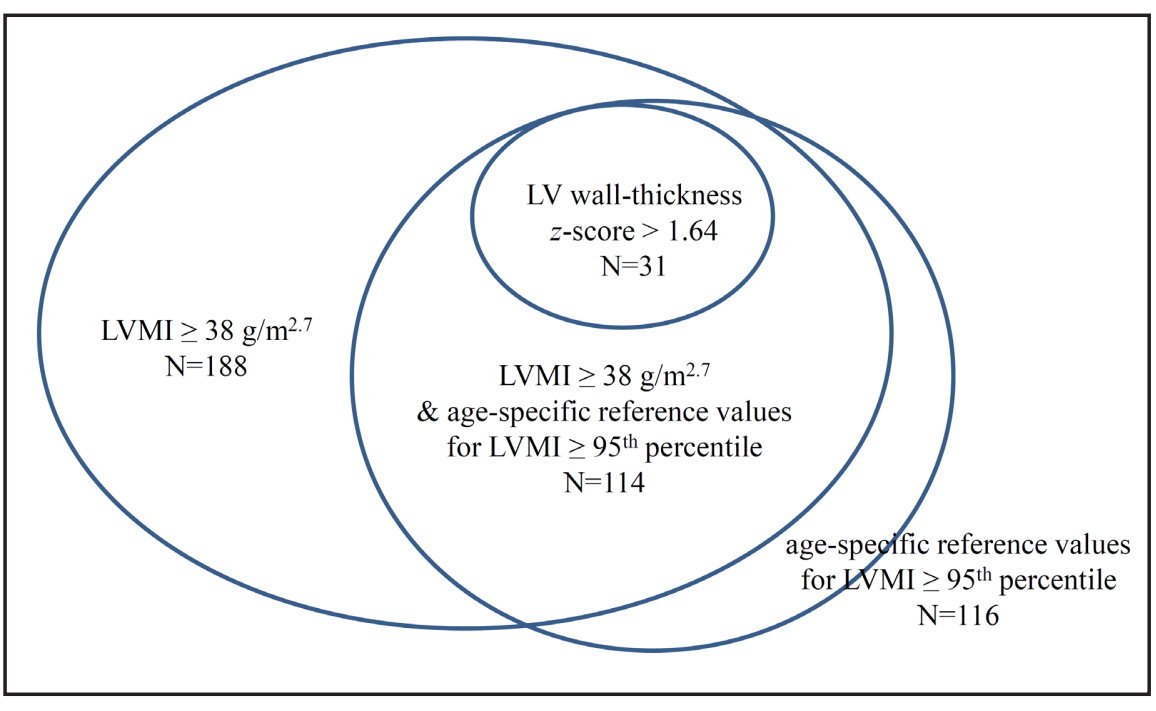
patients with $\mathrm{LVMI} \geq 38 \mathrm{~g} / \mathrm{m}^{2.7}$ and age-specific reference $\geq 95$ percentile, 31 patients $(27.2 \%)$ were compatible with LVH by the LV wall thickness $z$-score $>1.64$.

$28.6 \%$ of the children, concentric hypertrophy in $12.2 \%$, and concentric remodeling in $7.2 \%$. Concentric hypertrophy was associated with systolic hypertension.

\section{Prevalence and contributing factors of $\mathrm{LVH}$}

Based on an LVH diagnosis using LVMI $\geq 38 \mathrm{~g} / \mathrm{m}^{2.7}, 188$ patients $(41.0 \%)$ were diagnosed with $\mathrm{LVH}$, and the prevalence of LVH was higher in younger patients (especially $<2$ years of age) compared to older children $(P<0.001)$. When LVH was diagnosed with LVMI $\geq 38$ $\mathrm{g} / \mathrm{m}^{2.7}, \mathrm{LVH}$ was associated with younger age, a high level of the body mass index (BMI) $z$-score, high levels of iPTH, and the duration of primary disease by multivariable logistic regression (Table 3). Using the age-specific reference values for $L V M I \geq 95^{\text {th }}$ percentile, 116 patients $(25.3 \%)$ were diagnosed with $\mathrm{LVH}$, and there was no difference in the prevalence of $\mathrm{LVH}$ according to age. Among the patients with $\mathrm{LVMI} \geq 95^{\text {th }}$ percentile, 114 patients $(98 \%)$ were also compatible with LVH diagnosis using LVMI $\geq 38 \mathrm{~g} / \mathrm{m}^{2.7}$ (Figure 1). When LVH 


\section{Kidney Blood Pressure Research}

Table 4. Associated factors of left ventricular hypertrophy with the definition of the age-specific reference values for $\mathrm{LVMI} \geq 95^{\text {th }}$ percentile

\begin{tabular}{lllll}
\hline & \multicolumn{2}{l}{ Univariate logistic regression } & \multicolumn{2}{l}{ Multivariable logistic regression } \\
\cline { 2 - 5 } & Unadjusted OR $(95 \% \mathrm{CI})$ & $P$-value & Adjusted OR(95\% CI) & $P$-value \\
\hline Systolic hypertension & $3.318(1.872,5.881)$ & $<0.0001$ & $2.805(1.368,5.751)$ & 0.0049 \\
Anemia & $1.939(1.266,2.970)$ & 0.0023 & $2.178(1.216,3.902)$ & 0.0089 \\
BMI $z$-score & $1.359(1.127,1.638)$ & 0.0013 & $1.339(1.082,1.656)$ & 0.0073 \\
iPTH & $1.002(1.001,1.004)$ & 0.0007 & $1.003(1.001,1.005)$ & 0.0034 \\
Duration of primary disease & $0.899(0.853,0.948)$ & $<0.0001$ & $0.906(0.849,0.967)$ & 0.0029 \\
\hline
\end{tabular}

LVMI, Left ventricular mass index; OR, Odds ratio; CI, Confidence interval; BMI, Body mass index; iPTH, intact parathyroid hormone

Table 5. Associated factors of left ventricular hypertrophy with the definition of LV wall-thickness $z$-score $>1.64$

\begin{tabular}{lllll}
\hline & \multicolumn{2}{l}{ Univariate logistic regression } & \multicolumn{2}{l}{ Multivariable logistic regression } \\
\cline { 2 - 5 } & Unadjusted OR(95\% CI) & $P$-value & Adjusted 0R(95\% CI) & $P$-value \\
\hline Co-morbidity & $0.256(0.112,0.585)$ & 0.0012 & $0.035(0.004,0.277)$ & 0.0015 \\
Weight $z$ score & $1.592(1.212,2.090)$ & 0.0008 & $3.602(1.948,6.660)$ & $<0.0001$ \\
Hemoglobin & $0.639(0.524,0.778)$ & $<0.0001$ & $0.447(0.292,0.686)$ & 0.0002 \\
Duration of primary disease & $0.908(0.826,0.997)$ & 0.0441 & $1.268(1.063,1.512)$ & 0.0082 \\
LVMI $\left(\mathrm{g} / \mathrm{m}^{2.7}\right)$ & $1.119(1.084,1.155)$ & $<0.0001$ & $1.271(1.156,1.398)$ & $<0.0001$ \\
\hline
\end{tabular}

LV, Left ventricle; OR, Odds ratio; CI, Confidence interval; LVMI, Left ventricular mass index

Table 6. Concordance of the measures of left ventricular hypertrophy in children with chronic kidney disease

\begin{tabular}{lcc}
\hline & Kappa (95\% C.I) & $P$-value \\
\hline $\mathrm{LVMI} \geq 38 \mathrm{~g} / \mathrm{m}^{2.7}$ vs. age-specific reference $\geq 95$ percentile & $0.636(0.566,0.706)$ & $<0.0001$ \\
$\mathrm{LVMI} \geq 38 \mathrm{~g} / \mathrm{m}^{2.7}$ vs. LV wall thickness $Z$-score $>1.64$ & $0.189(0.129,0.249)$ & $<0.0001$ \\
Age-specific reference $\geq 95$ percentile vs. & $0.353(0.258,0.447)$ & $<0.0001$ \\
$\mathrm{LV}$ wall thickness $Z$-score $>1.64$ & &
\end{tabular}

CI, Confidence interval; LVMI, Left ventricular mass index; LV, Left ventricle

was diagnosed with the age-specific reference values for $L V M I \geq 95^{\text {th }}$ percentile, LVH was associated with systolic hypertension, anemia, high levels of BMI $z$-score, high levels of iPTH, and the duration of primary disease by multivariable logistic regression (Table 4). Thirtyone patients $(6.8 \%)$ were diagnosed with $\mathrm{LVH}$ using the $\mathrm{LV}$ wall-thickness $Z$-score $>1.64$. The patients with LVH using a $z$-score $>1.64$ were compatible with $\mathrm{LVMI} \geq 38 \mathrm{~g} / \mathrm{m}^{2.7}$ and age-specific reference values for $\mathrm{LVMI} \geq 95^{\text {th }}$ percentile. When using a $z$-score $>1.64, \mathrm{LVH}$ was associated with the presence of co-morbidity, high levels of the body weight $z$-score, low levels of hemoglobin, and the duration of primary disease (Table 5). Using the age-specific reference values for $\mathrm{LVMI} \geq 95^{\text {th }}$ percentile, the Kappa coefficient was 0.636 and 0.353 with the LVMI $\geq 38 \mathrm{~g} / \mathrm{m}^{2.7}$ method and the wall thickness $z$-score method, respectively. However, the Kappa coefficient showed a relatively low concordance value of 0.189 between the LVMI $\geq 38 \mathrm{~g} / \mathrm{m}^{2.7}$ method and the wall thickness $z$-score method. This finding suggests that there is a poor concordance between the diagnosis of LVH using the LV wall-thickness $z$-score and the $\mathrm{LVMI}^{2.7}$ method (Table 6).

\section{Discussion}

The results of this study show that there is poor concordance between the diagnosis of LVH using the wall-thickness $z$-score and the $\mathrm{LVMI}^{2.7}$ criteria. Recently, pediatric data for the prevalence of $\mathrm{LVH}$ and risk factors in CKD have been reported, and the definition 


\section{Kidney Blood Pressure Research}

of LVH in children with CKD varies across different studies. Although a study reported that the method for indexing LV mass by height ${ }^{3}$ is useful for determining the presence of LVH in children and adolescents, $\mathrm{LV}$ mass/height ${ }^{2.7}$ is usually regarded as an appropriate method for indexing LV mass for body size among the indexes based on height in children $[8,9,14]$. In the general population, LVH is commonly defined as LVMI above $38 \mathrm{~g} / \mathrm{m}^{2.7}$ and corresponds to the $95^{\text {th }}$ percentile of the pediatric population. However, a recent report suggested that $\mathrm{LV}$ mass/height ${ }^{2.7}$ should be compared with percentile curves in younger children because LVMI varies with age [13]. According to that study, the $95^{\text {th }}$ percentile of LVMI ranged from $80 \mathrm{~g} /$ $\mathrm{m}^{2.7}$ for newborns to $40 \mathrm{~g} / \mathrm{m}^{2.7}$ for 11-year-old children [13]. In our study, the prevalence of LVH was $41.0 \%$ and especially high in younger children below the age of 2 years when using the definition of LVMI $\geq 38 \mathrm{~g} / \mathrm{m}^{2.7}$, and these findings suggest that there is a risk of misdiagnosing younger healthy children as LVH if the cut-off of LVMI $\geq 38 \mathrm{~g} / \mathrm{m}^{2.7}$ is used for all patients from neonates to adolescents. When we define the LVH as above the 95th percentile, the prevalence of $\mathrm{LVH}$ was $25.3 \%$ and there was no difference in the prevalence of LVH according to age. This result was compatible with previous studies in pediatric CKD and defining LVH using percentile values could be a better method in the study of pediatric CKD patients. However, there remains some controversy as to the optimal method for indexing LV mass by body size and the cut-off value of LVH in children.

A recent report stated that LVMI $\left(\mathrm{g} / \mathrm{m}^{2.7}\right)$ showed a strong correlation with height in children $<140 \mathrm{~cm}$ tall, which suggests that LVMI does not work reasonably well in those cases [14]. However, there was no significant relationship between LVMI and height in children $\geq 140 \mathrm{~cm}$ tall [14]. According to this finding, Foster et al. suggested a novel method using LV mass-for-height centile curves that describe the distribution of LV mass relative to height among healthy, non-obese children, and, using this method, patients with an LV mass above the $95^{\text {th }}$ percentile for height $(z$-score $>1.64)$ were classified as having LVH [14]. Using this novel method, the prevalence of LVH in this study was $6.8 \%$, and there was no concordance between LVMI and the LV mass-for-height centile method. Considering that the cohort included a high proportion of patients $<140 \mathrm{~cm}$ tall, there is a possibility that the centile method could reflect the prevalence and associated factors of LVH in pediatric CKD. Additionally, LVH defined by the novel method of LV mass above the $95^{\text {th }}$ percentile for height was associated with co-morbidity, and there is a possibility that this novel method could predict morbidity in pediatric CKD patients.

In previous studies that assessed LV geometry in children with CKD, concentric LVH appeared more frequently in pre-dialysis patients. Mitsnefes et al. reported that eccentric LVH was more common in children on dialysis [4]. In our study, eccentric LVH was more common in pre-dialysis children, which could be due to a few reasons. Usually, eccentric remodeling is thought to be caused by an adaptation to preloading, such as fluid retention, and anemia. There is a possibility that more effective interventions for volume overload and renal anemia are needed in our patients. Another explanation is that the proportion of LV geometry may be associated with the cut-off used to define LVH. In our study, the cut-off of $\mathrm{LVMI} \geq 38 \mathrm{~g} / \mathrm{m}^{2.7}$ was used, and the other definitions of LVH can lead to a different proportion of LVH geometry.

In our study, the common risk factors for LVH included the BMI $z$-score, levels of iPTH, anemia, and the duration of primary disease, and these findings are compatible with previous studies. The ESCAPE Trial Group reported that the prevalence of LVH in children with CKD is related to male gender, anemia, and high BMI [10]. Usually, hypertension has been a minor contributor to LVH in early CKD, and both our study and the ESCAPE Trial are suggestive of this finding. However, there was a few studies that hypertension may be a major contributor $[25,26]$. Mitsnefes et al. reported that LVH was more common in children with either confirmed or masked hypertension compared with those with normal BP, and casual BP measurements alone are insufficient to predict LVH [25]. In our study, the lack of data for masked hypertension could influence the results, and the future study of the prevalence of masked hypertension based on ambulatory BP monitoring and its association 


\section{Kidney Blood Pressure Research}

with LVH is necessary. Additionally, a study by Kupferman et al. suggested that BP control could cause LVH regression in children with CKD [26]. In our study, renal anemia and the long duration of the disease could especially play a role in the high proportion of eccentric $\mathrm{LVH}$. A previous report stated that increased cardiac output might predispose pediatric CKD patients to LVH, and no association with PTH or anemia was observed [27]. A longitudinal study, including the association between BP control and LVH change, and the risk factors and morbidity associated with LVH based on the data from the KNOW-Ped CKD should be conducted in the future.

This study had several limitations. First, there is lack of ambulatory blood pressure monitoring, and the data for masked hypertension might be insufficient. Second, twodimensional echocardiography was performed by pediatric cardiologists in each center and there was no central reading of the echocardiography. The lack of assessment by a single investigator blinded to medical therapy could influence the validity of the echocardiography data.

There has been little study of the concordance of the different LVH definition in children with CKD [28-30]. Simpson et al. reported that 5 different methods of LVM indexation influenced the categorization of pediatric CKD patients with respect to LVH [28]. Ruebner et al. suggested that indexing LVM to estimated lean body mass could be an alternative to height indexing in pediatric CKD patients because indexing LVM to height might cause a sex difference in the proportion of LVH without the increased prevalence of cardiovascular disease risk factors [29]. However, there is no data as to which method could predict cardiovascular events in pediatric CKD patients. It is important to accurately diagnose LVH in pediatric CKD patients because LVH is an early marker of cardiac dysfunction, and appropriate intervention can prevent cardiac deterioration.

\section{Conclusion}

Further study is necessary to estimate the correlation between LVH and cardiac dysfunction and to find a better method of defining LVH in the pediatric CKD cohort, thereby predict cardiac dysfunction.

\section{Disclosure Statement}

None of the authors have conflicts of interest to disclose.

\section{Acknowledgements}

This work was supported by the Research Program funded by the Korean Centers for Disease Control and Prevention (2011E3300300, 2012E3301100, 2013E3301600, 2013E3301601, and 2013E3301602).

\section{References}

1 Parekh RS, Carroll CE, Wolfe RA, Port FK: Cardiovascular mortality in children and young adults with endstage kidney disease. J Pediatr 2002;141:191-197.

2 Mencarelli F, Fabi M, Corazzi V, Doyon A, Masetti R, Bonetti S, Castiglioni L, Pession A, Montini G: Left ventricular mass and cardiac function in a population of children with chronic kidney disease. Pediatr Nephrol 2014;29:893-900. 


\section{Kidney \\ Blood Pressure Research}

3 Shroff R, Weaver DJ, Jr., Mitsnefes MM: Cardiovascular complications in children with chronic kidney disease. Nat Rev Nephrol 2011;7:642-649.

4 Mitsnefes MM, Kimball TR, Border WL, Witt SA, Glascock BJ, Khoury PR, Daniels SR: Impaired left ventricular diastolic function in children with chronic renal failure. Kidney Int 2004;65:1461-1466.

5 Dogan CS, Akman S, Simsek A, Ozdem S, Comak E, Gokceoglu AU, Kardelen F, Koyun M: Assessment of left ventricular function by tissue doppler echocardiography in pediatric chronic kidney disease. Ren Fail 2015;37:1094-1099.

6 Hewing B, Dehn AM, Staeck O, Knebel F, Spethmann S, Stangl K, Baumann G, Dreger H, Budde K, Halleck F: Improved left ventricular structure and function after successful kidney transplantation. Kidney Blood Press Res 2016;41:701-709.

7 Rebić D, Matovinović MS, Rašić S, Kes P, Hamzić-Mehmedbašić A: The effect of preserved residual renal function on left ventricular structure in non-anuric peritoneal dialysis patients. Kidney Blood Press Res 2015;40:500-508.

8 de Simone G, Devereux RB, Daniels SR, Koren MJ, Meyer RA, Laragh JH: Effect of growth on variability of left ventricular mass: Assessment of allometric signals in adults and children and their capacity to predict cardiovascular risk. J Am Coll Cardiol 1995;25:1056-1062.

9 de Simone G, Daniels SR, Devereux RB, Meyer RA, Roman MJ, de Divitiis O, Alderman MH: Left ventricular mass and body size in normotensive children and adults: Assessment of allometric relations and impact of overweight. J Am Coll Cardiol 1992;20:1251-1260.

10 Matteucci MC, Wuhl E, Picca S, Mastrostefano A, Rinelli G, Romano C, Rizzoni G, Mehls O, de Simone G, Schaefer F, Group ET: Left ventricular geometry in children with mild to moderate chronic renal insufficiency. J Am Soc Nephrol 2006;17:218-226.

11 Matteucci MC, Chinali M, Rinelli G, Wuhl E, Zurowska A, Charbit M, Pongiglione G, Schaefer F, Group ET: Change in cardiac geometry and function in ckd children during strict bp control: A randomized study. Clin J Am Soc Nephrol 2013;8:203-210.

12 Moyer VA, Force USPST: Screening for primary hypertension in children and adolescents: U.S. Preventive services task force recommendation statement. Pediatrics 2013;132:907-914.

13 Khoury PR, Mitsnefes M, Daniels SR, Kimball TR: Age-specific reference intervals for indexed left ventricular mass in children. J Am Soc Echocardiogr 2009;22:709-714.

14 Foster BJ, Mackie AS, Mitsnefes M, Ali H, Mamber S, Colan SD: A novel method of expressing left ventricular mass relative to body size in children. Circulation 2008;117:2769-2775.

15 Mirchandani D, Bhatia J, Leisman D, Kwon EN, Cooper R, Chorny N, Frank R, Infante L, Sethna C: Concordance of measures of left-ventricular hypertrophy in pediatric hypertension. Pediatr Cardiol 2014;35:622-626.

-16 Kang HG, Choi HJ, Han KH, Kim SH, Cho HY, Cho MH, Shin JI, Lee JH, Lee J, Oh KH, Park YS, Cheong HI, Ahn C, Ha IS: Know-ped ckd (korean cohort study for outcomes in patients with pediatric ckd): Design and methods. BMC Nephrol 2016;17:35.

-17 National Kidney F: K/doqi clinical practice guidelines for chronic kidney disease: Evaluation, classification, and stratification. Am J Kidney Dis 2002;39:S1-266.

-18 Fadrowski JJ, Neu AM, Schwartz GJ, Furth SL: Pediatric GFR estimating equations applied to adolescents in the general population. Clin J Am Soc Nephrol 2011;6:1427-1435.

19 National High Blood Pressure Education Program Working Group on High Blood Pressure in Children and Adolescents: The fourth report on the diagnosis, evaluation, and treatment of high blood pressure in children and adolescents. Pediatrics 2004;114:555-576.

20 Davignon A, Rautaharju P, Boiselle E, Soumis F, Megelas M, Choquette A: Normal ECG standards for infants and children. Pediatr Cardiol 1979;1:123-152.

21 Lopez L, Colan SD, Frommelt PC, Ensing GJ, Kendall K, Younoszai AK, Lai WW, Geva T: Recommendations for quantification methods during the performance of a pediatric echocardiogram: A report from the pediatric measurements writing group of the american society of echocardiography pediatric and congenital heart disease council. J Am Soc Echocardiogr 2010;23:465-495; quiz 576-577.

22 Devereux RB, Reichek N: Echocardiographic determination of left ventricular mass in man. Anatomic validation of the method. Circulation 1977;55:613-618. 


\section{Kidney \\ Blood Pressure Research}

23 Lang RM, Bierig M, Devereux RB, Flachskampf FA, Foster E, Pellikka PA, Picard MH, Roman MJ, Seward J, Shanewise J, Solomon S, Spencer KT, St John Sutton M, Stewart W, American Society of Echocardiography's $\mathrm{N}$, Standards C, Task Force on Chamber Q, American College of Cardiology Echocardiography C, American Heart A, European Association of Echocardiography ESoC: Recommendations for chamber quantification. Eur J Echocardiogr 2006; 7:79-108.

24 Daniels SR, Meyer RA, Liang YC, Bove KE: Echocardiographically determined left ventricular mass index in normal children, adolescents and young adults. J Am Coll Cardiol 1988;12:703-708.

-25 Mitsnefes M, Flynn J, Cohn S, Samuels J, Blydt-Hansen T, Saland J, Kimball T, Furth S, Warady B; CKiD Study Group: Masked hypertension associates with left ventricular hypertrophy in children with CKD. J Am Soc Nephrol 2010;21:137-44.

26 Kupferman JC, Aronson Friedman L, Cox C, Flynn J, Furth S, Warady B, Mitsnefes M; CKiD Study Group: BP control and left ventricular hypertrophy regression in children with CKD. J Am Soc Nephrol 2014;25:16774.

27 Weaver DJ, Jr., Kimball TR, Koury PR, Mitsnefes MM: Cardiac output and associated left ventricular hypertrophy in pediatric chronic kidney disease. Pediatr Nephrol 2009;24:565-570.

28 Simpson JM, Savis A, Rawlins D, Qureshi S, Sinha MD: Incidence of left ventricular hypertrophy in children with kidney disease: impact of method of indexation of left ventricular mass. Eur J Echocardiogr 2010;11:271-277.

-29 Ruebner RL, Ng D, Mitsnefes M, Foster BJ, Meyers K, Warady B, Furth SL: Cardiovascular Disease Risk Factors and Left Ventricular Hypertrophy in Girls and Boys With CKD. Clin J Am Soc Nephrol 2016;11:1962-1968.

-30 McLaughlin R, Hamiwka L, Samuel S, Fruitman D, Grisaru S: A longitudinal retrospective analysis of left ventricular mass in a cohort of pediatric kidney transplant recipients. Pediatr Transplant 2014;18:810815. 